Brazilian Journal
of Chemical
Engineering

\title{
PRODUCTION OF HYDROGEN IN THE REACTION BETWEEN ALUMINUM AND WATER IN THE PRESENCE OF NaOH AND KOH
}

\author{
C. B. Porciúncula , N. R. Marcilio, I. C. Tessaro and M. Gerchmann \\ Department of Chemical Engineering, Federal University of Rio Grande do Sul, UFRGS, \\ Phone/Fax: + (55) (51) 3308-3444, + (55) (51) 3308-3277, Central Campus, \\ Luis Englert, St., ZIP Code: 90040-040, Porto Alegre - RS, Brazil. \\ *E-mail: cleiton@enq.ufrgs.br; nilson@enq.ufrgs.br; isabel@enq.ufrgs.br; marcos.gemeo@gmail.com
}

(Submitted: November 9, 2011 ; Revised: December 20, 2011 ; Accepted: December 28, 2011)

\begin{abstract}
The objective of this work is to investigate the production of hydrogen as an energy source by means of the reaction of aluminum with water. This reaction only occurs in the presence of $\mathrm{NaOH}$ and $\mathrm{KOH}$, which behave as catalysts. The main advantages of using aluminum for indirect energy storage are: recyclability, nontoxicity and easiness to shape. Alkali concentrations varying from 1 to $3 \mathrm{~mol}^{-1}$ were applied to different metallic samples, either foil $(0.02 \mathrm{~mm}$ thick) or plates $(0.5$ and $1 \mathrm{~mm}$ thick), and reaction temperatures between 295 and $345 \mathrm{~K}$ were tested. The results show that the reaction is strongly influenced by temperature, alkali concentration and metal shape. $\mathrm{NaOH}$ commonly promotes faster reactions and higher real yields than $\mathrm{KOH}$.

Keywords: Hydrogen; Aluminum; Alkaline corrosion.
\end{abstract}

\section{INTRODUCTION}

New methods to generate energy have been investigated in the last decade due to concerns about the depletion of fuels. Hydrogen is a promising source of energy because this gas affords a clean and high heat of combustion. Energy continues to play an ever important role in our society. The majority of energy consumed is derived from sources such as oil, gas and coal, with a small contribution from nuclear, biomass, solar and wind energy. The use of hydrogen to generate energy is an interesting approach because of the salient features of this gas. Hydrogen has a high calorific power (HHV=141.9 $\mathrm{MJ}^{-1} \mathrm{~kg}^{-1}$ and

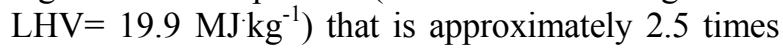
the value of gasoline. Its combustion in the presence of pure oxygen is completely clean with the concomitant formation of water (although, depending on the temperature, very small quantities of $\mathrm{NO}_{\mathrm{x}}$ may be formed when hydrogen is burned in the presence of air). Hydrogen also has the capacity to be produced in situ or on demand, according to local energy needs.

Despite these advantages, hydrogen has some drawbacks, which have delayed a worldwide economy based on this gas. The storage and transport of hydrogen requires energy and special materials (Tzimas and Filiou, 2003) due to its very low boiling point $(20 \mathrm{~K})$. In addition, hydrogen must be produced by a chemical reaction because it is not found in its free molecular form on Earth. The electrochemical oxidation of hydrogen in low temperature fuel cells still depends on noble catalysts such as Pt, which are expensive and rare.

The majority of the hydrogen produced at present comes from electrolysis and the reforming reactions of oil and biomass (Holladay et al., 2009). The gasification of coal and biomass (Gerum et al., 2008; Giltrap et al., 2003; Zainal et al., 2001; Porciúncula et al., 2009) is also a method to obtain hydrogen. However, the reaction products consist of a mixture

*To whom correspondence should be addressed 
of several gases other than hydrogen, such as methane, carbon dioxide and monoxide, sulfur and nitrogen compounds.

The reaction of metals with water to produce hydrogen has recently been extensively investigated. When metallic elements from groups IA and IIA of the periodic table come in contact with water (e.g., $\mathrm{Na}, \mathrm{K}, \mathrm{Li}$ ) the corresponding metal hydroxide and hydrogen are formed. Such a reaction only proceeds with aluminum in the presence of a strong alkaline compound, such as $\mathrm{NaOH}$ or $\mathrm{KOH}$ (Soler et al., 2009; Soler et al., 2007) because this metal has a very thin passive layer of $\mathrm{Al}_{2} \mathrm{O}_{3}$ on its surface that prevents the direct attack of water molecules (Grosjean et al., 2005; Wang et al., 2009). The reaction between aluminum and water can occur in the absence of any alkali if special alloy elements (e.g., indium and gallium) are added to aluminum in small quantities (Parmuzina et al., 2008; Kravchenko et al., 2005; Dow et al., 1997). The reaction between aluminum and water obeys the following stoichiometry:

$$
\mathrm{Al}+3 \mathrm{H}_{2} \mathrm{O} \rightarrow \mathrm{Al}(\mathrm{OH})_{3}+\frac{3}{2} \mathrm{H}_{2}
$$

There are several mechanisms that have been proposed in the literature for the reaction shown above. According to Deng and Ferreira (2007), the formation of several intermediates, such as pseudoboehmite $(\mathrm{AlOOH})$, can be predicted from a mathematical model of the critical pressure of hydrogen bubbles inside the passivation layer of oxide. The addition of $\mathrm{NaAl}(\mathrm{OH})_{4}$, the replacement of $\mathrm{NaOH}$ by $\mathrm{NaAlO}_{2}$ and the addition of other compounds such as salts has been described in the literature (Soler et al., 2007, 2009), and all give similar results for the yields and reaction rates.

There are several advantages of using aluminum as a primary source of energy. First, its by-product, $\mathrm{Al}(\mathrm{OH})_{3}$, may be used to produce other aluminum salts for several applications, ranging from water treatment $\left(\right.$ as $\left.\mathrm{Al}_{2}\left(\mathrm{SO}_{4}\right)_{3}\right)$ to the use of the hydroxide in pharmaceuticals. Second, the recovery of aluminum from $\mathrm{Al}(\mathrm{OH})_{3}$ can be performed by electrolysis or other convenient process. Third, aluminum can be obtained from recyclable materials, such as soft drink or beer cans (Martínez et al., 2005, 2007). Fourth, different degrees of purity of the metal can be used, so that commercial alloys instead of pure or high-purity alloys can be used. Fifth, the hydrogen generated by reaction (1) is pure; therefore, it could be used in devices that require high purity, including some types of fuel cells for portable electronic devices or even for mobile applications. Finally, because the alkali is not consumed in the reaction and acts as a catalyst, it can be fully recovered. An overview example of how the cycle of utilizing aluminum scraps as a primary source of energy is illustrated in Figure 1.

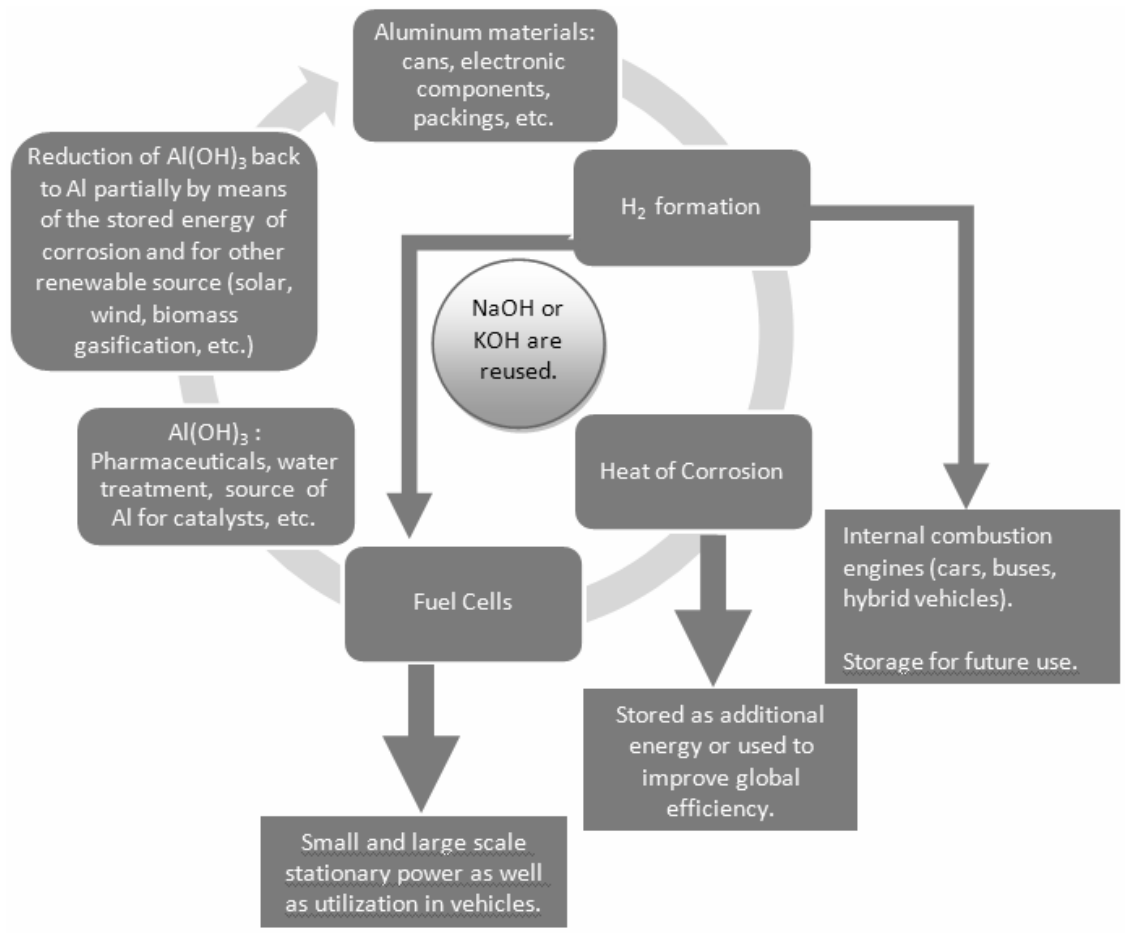

Figure 1: Overview of the proposed energy chain based on recyclable aluminum materials. 
Aluminum might be used as a recyclable energy source based on two principal routes: materials of daily use (cans, packing, waste electronic components); reduction of the corrosion by-product, $\mathrm{Al}(\mathrm{OH})_{3}$, back to metallic aluminum in order to manufacture more goods or to be reused as energy. The reduction of $\mathrm{Al}(\mathrm{OH})_{3}$ might be by an electrochemical route. The necessary energy may be obtained from other established and clean sources (gasification, solar, wind) and also partially from the extra energy stored in the aluminum corrosion, where $\Delta \mathrm{H}_{\text {reaction }}=-418 \mathrm{kJmol}^{-1} \mathrm{Al}$. Also, the excess of $\mathrm{Al}(\mathrm{OH})_{3}$ is applicable to produce pharmaceuticals to treat stomach diseases and for the treatment of the water by removing contaminants as a flocculant component, $\mathrm{Al}_{2}\left(\mathrm{SO}_{4}\right)_{3}$. Aluminum is a precursor of many catalysts of several organic reactions, which is an interesting destination.

\section{EXPERIMENTAL PROCEDURE}

Samples of commercial aluminum with masses varying from 34 to $37 \mathrm{mg}$ were reacted to evaluate the behavior of the alkaline corrosion reaction at different temperatures, alkali concentrations and metal shapes. The reactions were performed in an inverted and sealed $60-\mathrm{mL}$ syringe where both alkali solutions and aluminum samples were inserted. The syringes were immersed in a thermostated water bath up to the level of the solution $(5 \mathrm{~mL})$, as depicted in Figures 2 and 3:

Syringe needles were inserted in silicone stoppers to avoid the leaking of solution into the thermostated

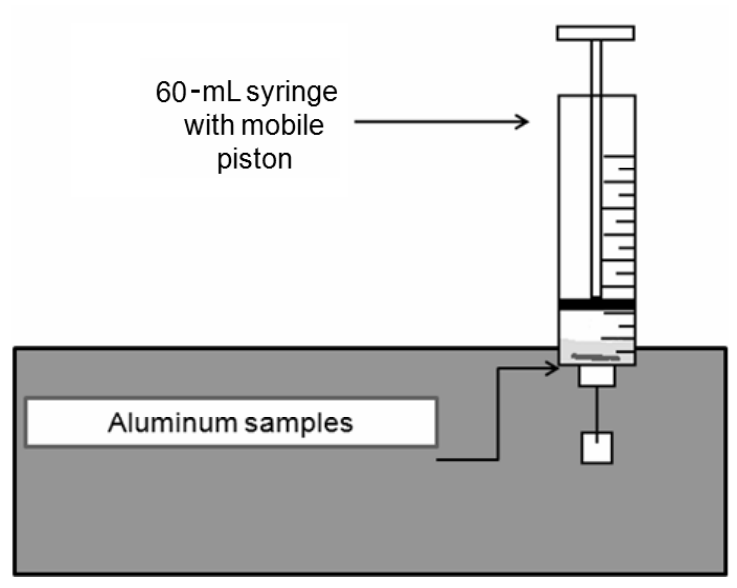

Figure 2: Schematic of the experimental apparatus. water bath. Hydrogen formation was measured by the displacement of the piston over time, registering the corresponding volume of gas. Three experiments were conducted for each concentration of alkali at each temperature. A correction factor $\left(T_{\text {water bath }} /\right.$ $\mathrm{T}_{\text {room temperature) was }}$ used because the temperature at which hydrogen formed in the lower region of the syringe immersed in the water bath was different from that of the rest of the syringe at room temperature. Taking this correction factor into account, the correct number of moles of hydrogen was calculated.

Three different samples of metal with different thicknesses were used: aluminum foil $(0.02 \mathrm{~mm})$, plates $(0.5 \mathrm{~mm})$ and thicker plates $(1 \mathrm{~mm})$, all of which had the same mass. The following temperatures were used: $295,305,315$ and $325 \mathrm{~K}$ for foils and 0.5 -mm thick plates; $315,325,335$ and $345 \mathrm{~K}$ for $1-\mathrm{mm}$ thick plates. Different temperatures were used for different thicknesses of metallic plates due to the very long reaction time for thicker samples at room temperature ( 295 and $305 \mathrm{~K}$ ). This drawback caused some difficulties in the evaluation of the reaction rates, so a higher temperature was chosen for the 1-mm thick aluminum plates to avoid this problem. For each temperature, five concentrations of alkali (NaOH or $\mathrm{KOH})$ were tested: 1, 1.5, 2, 2.5 and $3 \mathrm{~mol} \mathrm{~L}^{-1}$. Three experiments were conducted for each temperature and concentration. The aluminum samples were completely consumed in all the experiments. Nonetheless, it is possible to view the change in the color of the samples as the reaction proceeds. This color becomes a dark gray as the metal is consumed, and the thickness decreases.

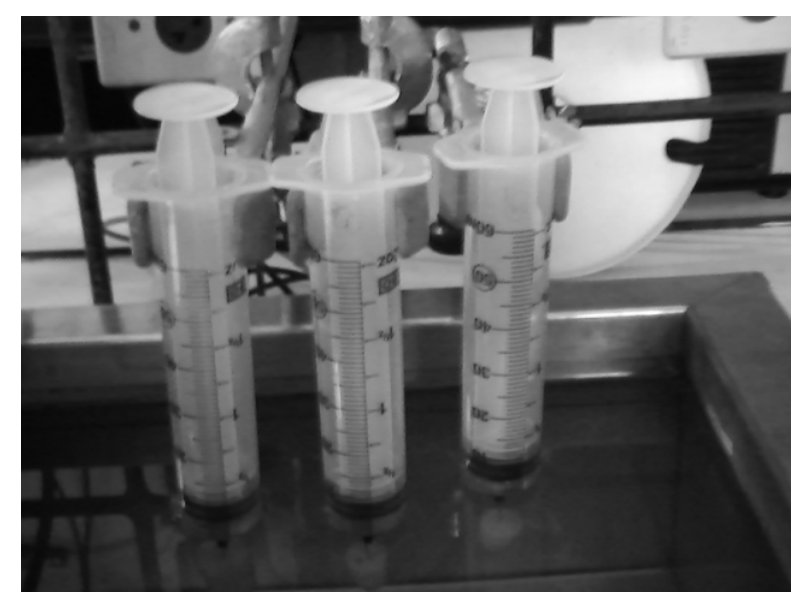

Figure 3: Photo of the experimental apparatus. 
One of the objectives of this study is to evaluate whether reaction rates are influenced by different metal thicknesses. Samples with the same mass and different thicknesses present different reaction rates. Other objectives include: evaluation of hydrogen yields in different reaction conditions; reaction rate behavior in the presence of different catalysts, and estimation of the kinetic parameters of the reaction.

\section{RESULTS AND DISCUSSION}

\section{Evolution of Hydrogen Over Time}

Time course curves for hydrogen evolution under different reaction conditions for the three thicknesses

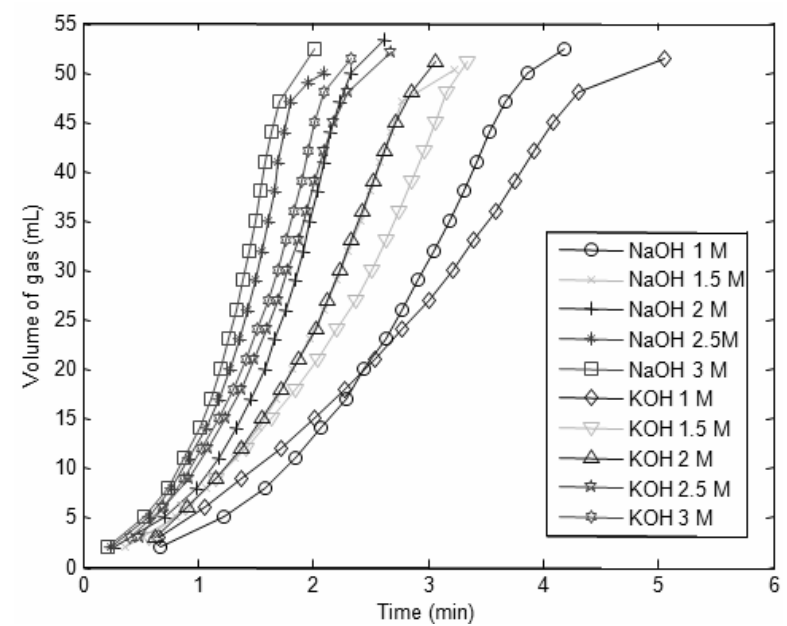

Figure 4: Evolution of hydrogen from aluminum foils with different catalyst concentrations at $325 \mathrm{~K}$ of aluminum tested are illustrated in Figures 4-6 below.

From the results above, we can verify that a greater hydrogen volume is produced in the same amount of time with a higher alkali concentration (and therefore, the reaction rate is higher). When one compares both alkalis to each other, one observes that $\mathrm{NaOH}$ has a tendency to speed up the reaction more effectively than $\mathrm{KOH}$, particularly with a larger metal thickness. The curves of hydrogen evolution shown in the figures above also have similar behaviors characterized by an initial fast and quasi-linear evolution followed by an asymptotic plateau. The reaction time course with aluminum foil in Figure 4 shows a clear change in the concavity of the curves, which is not observed with the other samples.

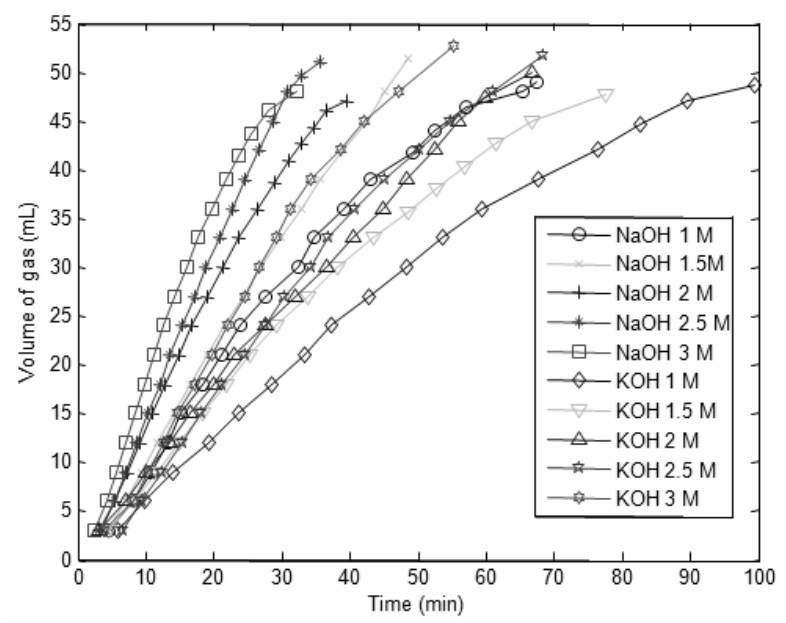

Figure 5: Evolution of hydrogen from aluminum plates $(0.5 \mathrm{~mm}$ thick $)$ with different catalyst concentrations at $325 \mathrm{~K}$

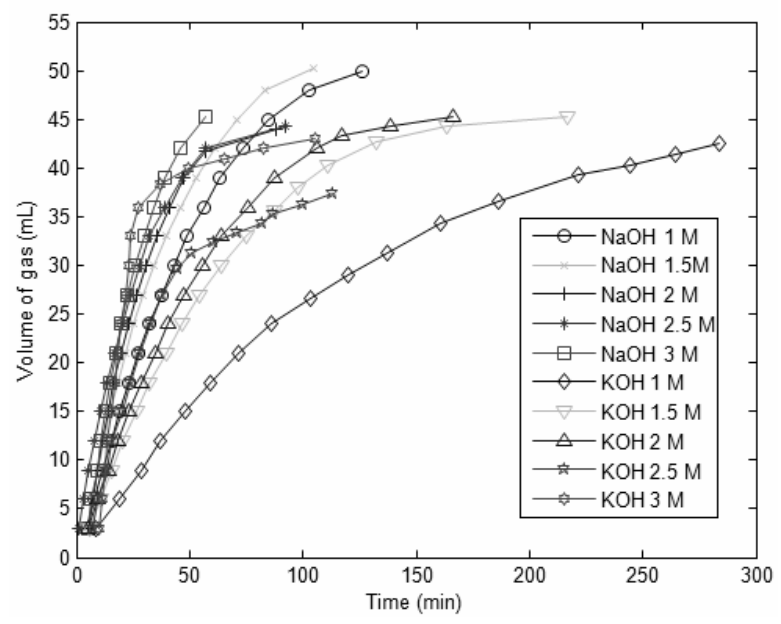

Figure 6: Evolution of hydrogen from aluminum plates (1-mm thick) with different catalyst concentrations at $325 \mathrm{~K}$ 
As observed in Figs. 4 and 5, the increase in the total reaction time due to slower reaction rates is related to the initial linearity of the curves. This is more easily understood by plotting the reaction rates versus time, as is illustrated in Figures 7-9.

The total reaction times for the data shown in Figures 8 and 9 were 950 and 335 minutes, respectively; however, for visual clarity these plots do not show the entire data set. As shown in Figures. 7-9, the maximum reaction rates are observed for higher temperatures, which is expected from chemical kinetic theory. A comparison between the data for $\mathrm{KOH}$ and $\mathrm{NaOH}$ solutions shows that the chemical reaction has a tendency to proceed more quickly in the presence of $\mathrm{NaOH}$.
This may indicate that the mechanism of catalysis is slightly different for each alkali. This is confirmed by the fact that the activation energies for every experiment are larger in the presence of $\mathrm{KOH}$, according to Tables 8 and 9. The higher reaction rate in the presence of $\mathrm{KOH}$ solutions was also reported by Soler et al (2007), but without any explanation for such behavior. The activation energy of corrosion is related to the exchange current density $\mathrm{i}_{0}$ : the larger the activation energy, the smaller $i_{0}$, so the corrosion proceeds slower, and vice-versa. (Brett and Brett, 1993). Thus, it is possible to affirm that the value of $i_{0}$ in the open corrosion process in the presence of $\mathrm{KOH}$ is less than $\mathrm{i}_{0}$ in the presence of $\mathrm{NaOH}$.

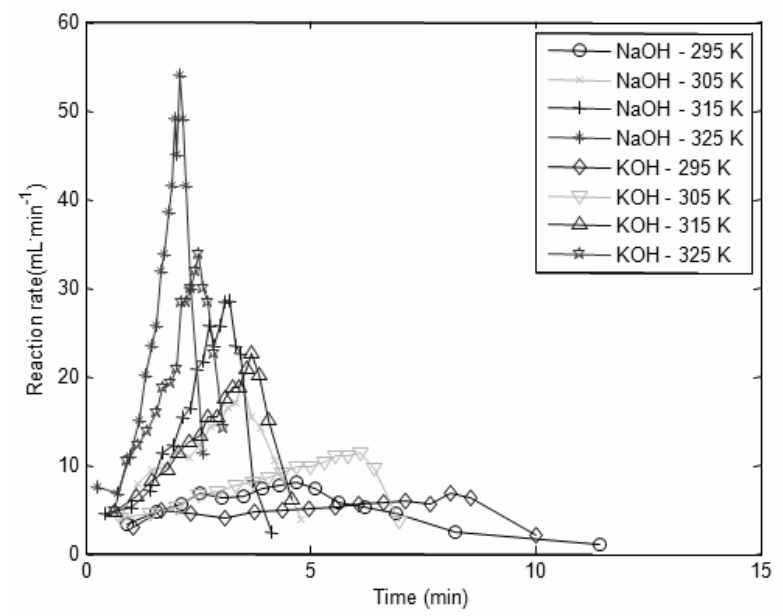

Figure 7: Experimental reaction rates for $\mathrm{NaOH}$ and $\mathrm{KOH}\left(2 \mathrm{~mol}^{-1}\right)$ at different temperatures for aluminum foil

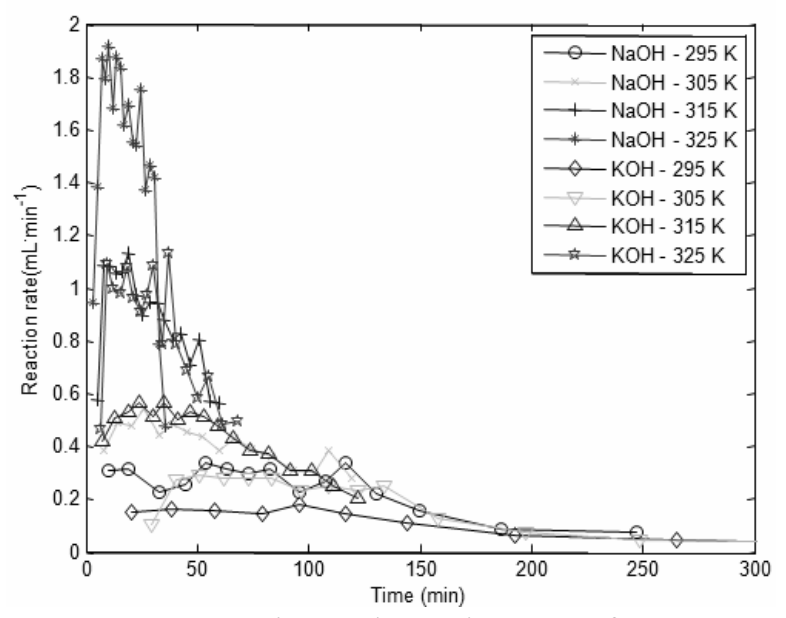

Figure 8: Experimental reaction rates for $\mathrm{NaOH}$ and $\mathrm{KOH}\left(2.5 \mathrm{~mol}^{-1}\right)$ at different temperatures for $0.5 \mathrm{~mm}$ thick aluminum plates $(950 \mathrm{~min}$. total reaction time)

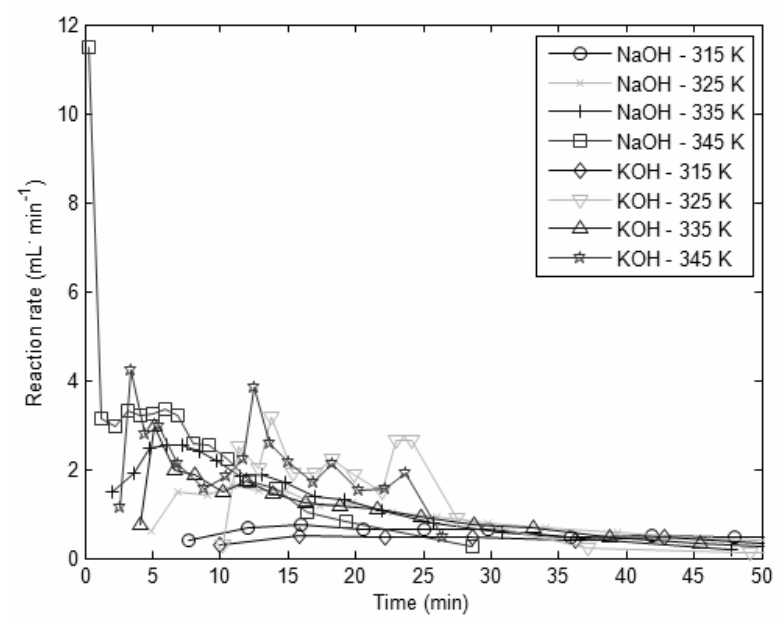

Figure 9: Experimental reaction rates for $\mathrm{NaOH}$ and $\mathrm{KOH}\left(3 \mathrm{~mol}^{-1}\right)$ at different temperatures for $1 \mathrm{~mm}$ thick aluminum plates ( $335 \mathrm{~min}$. total reaction time) 
Additionally, the plots showing the volume of hydrogen evolved over time demonstrate that the process has two distinct stages: an initial stage limited by the chemical reaction rate (linear section of the curves in Figs. 4-6) and a mass transfer limiting step in the final portion of the curves (Soler et al. 2009). These mass transfer effects are the result of complex interactions between the precipitation of $\mathrm{Al}(\mathrm{OH})_{3}$ on the metal and the movement of hydrogen bubbles through the passivation layer and the solution. In the literature, the chemical controlling step is generally considered to be a first order chemical reaction with respect to the $\left[\mathrm{OH}^{-}\right]$ concentration (Soler et al.,2007, 2009). The limiting mass transfer effect is a strong characteristic of the reaction due to deposition of the precipitate of aluminum hydroxide on the aluminum surface, as already reported by other authors. For example, in the work of Emregül and Aksüt (2000), this effect was observed in polarization measurements at high electrochemical potentials. There are two possible ways to minimize this effect: temperature and agitation. Upon increasing temperature, the turbulence in the vicinity of the aluminum layer is promoted so that the precipitation of $\mathrm{Al}(\mathrm{OH})_{3}$ becomes more difficult. The agitation also promotes local turbulence. Nevertheless, the insertion of an agitation system would raise the complexity of the system, as well as energetic needs.

The reproducibility of the triplicates for each concentration and temperature was adequate. The major deviations between experiments were observed at the end of the reaction because the difficulties in collecting the volume data are greater due to the decrease in reaction rate. The standard deviations varied between $0.03 \mathrm{~min}$ and $1.4 \mathrm{~min}$ for every experiment.

\section{Metal Analysis}

The precipitation of $\mathrm{Al}(\mathrm{OH})_{3}$ crystals on the aluminum surface in the limiting reaction step is illustrated in Figure 10. The confirmation of the presence of bayerite (one of the different crystalline structures of aluminum hydroxide) was verified by means of an XRD-Analysis, as shown in Figure 11.

The peaks corresponding to $\mathrm{d}=2.028$ and $\mathrm{d}=1.434$ are due to the presence of $\mathrm{Fe}$ atoms as the main impurity. The presence of other elements in the aluminum samples used is presented in Table 1, where Fe might be present up to $1 \%$.

Evaluations of the presence of several components were carried out with Scanning Electron Microscopy and Energy Dispersive X-Ray Spectroscopic Analysis (SEM-EDS, microscopes JSM 5800 and JSM 6060). The results confirm the largest proportion of $\mathrm{Al}_{2} \mathrm{O}_{3}$ on the aluminum surfaces $(97.05 \%-98.77 \%)$, followed by $\mathrm{MgO}(1.23 \%$ $2.27 \%$ ). The presence of other elements ( $\mathrm{C}, \mathrm{K}$ and $\mathrm{O}$ ) was also verified by EDS analysis.

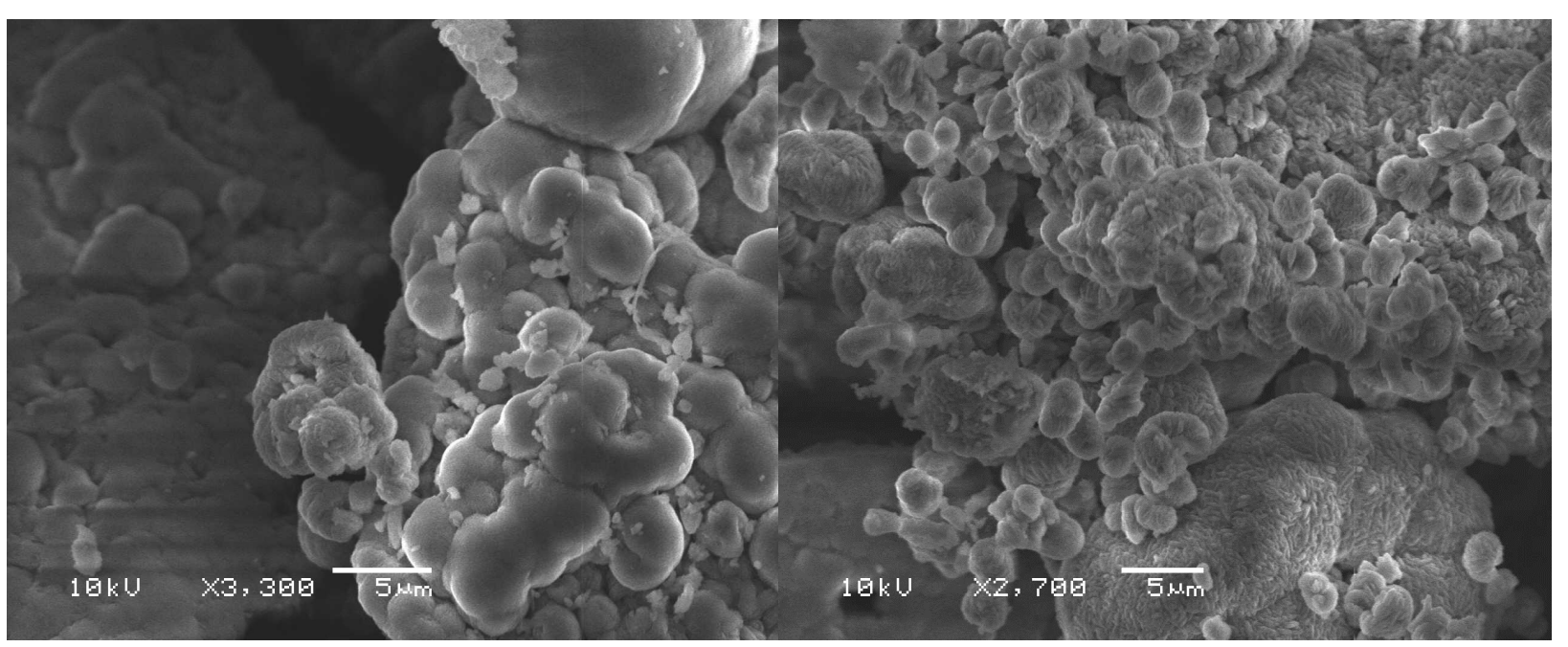

(a) (b)

Figure 10: Micrographs of $\mathrm{Al}(\mathrm{OH})_{3} \cdot 3 \mathrm{H}_{2} \mathrm{O}$ as bayerite precipitate on the aluminum surface after reaction with $\mathrm{NaOH}(\mathrm{a})$; and $\mathrm{KOH}(\mathrm{b})$ 


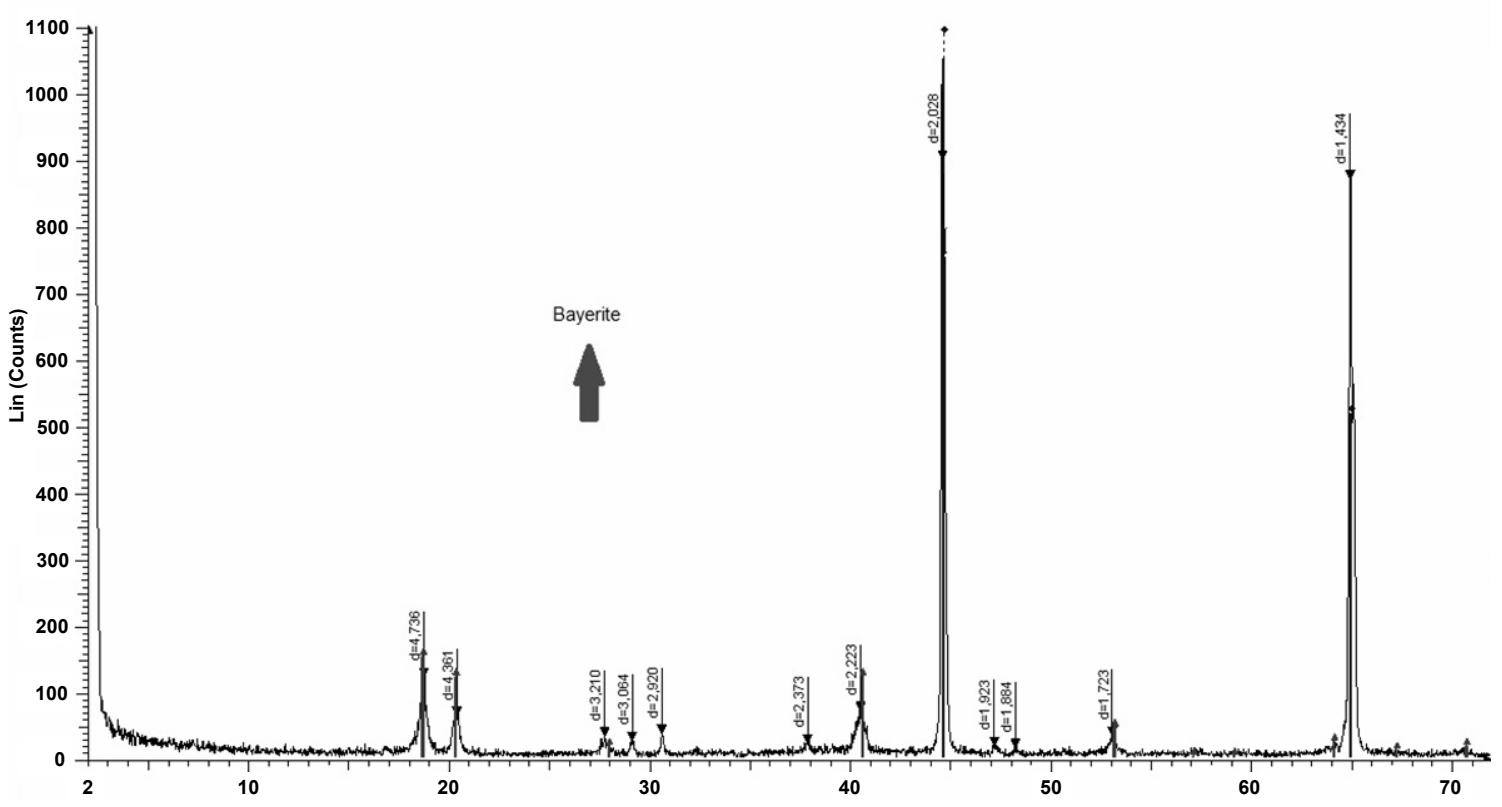

Figure 11: XRD Analysis of the aluminum surface reacted with $\mathrm{NaOH}$ solution. - Bayerite precipitate is highlighted in the following peaks: $d=4.736 ; d=4.361 ; d=3.21 ; d=2.223 ; d=1.723$

Table 1: Composition (\%) of the aluminum alloys - Minimum and maximum values allowed per element

\begin{tabular}{|l|c|c|c|c|c|c|c|c|}
\hline Element & Si & Fe & $\mathbf{C u}$ & $\mathbf{M n}$ & $\mathbf{M g}$ & $\mathbf{C r}$ & $\mathbf{Z n}$ & $\mathbf{T i}$ \\
\hline Alloy & $0.5-0.9$ & $0.6-1.0$ & 0.1 & 0.2 & 0.05 & 0.05 & 0.1 & 0.08 \\
Poils & $0.25-0.6$ & $0.4-0.7$ & $0.02-0.3$ & $0.05-1.5$ & $0.05-0.8$ & 0.2 & $0.05-0.4$ & $0.03-0.1$ \\
\hline
\end{tabular}

Available at: http://www.alcoa.com/brazil/catalog/pdf/BoletimFOLHAS2011.pdf (oct/2011) http://www.alcoa.com/brazil/catalog/pdf/BoletimCHAPAS2011.pdf (oct/2011)

\section{Hydrogen Yields}

The results of the experimental yields for reactions with aluminum foil are shown in Tables 2 and 3.

Based on the data in Tables 2 and 3 , the hydrogen yields varied from approximately $81 \%$ to a maximum of $96 \%$. Experimental data reported in the literature (Wang et al., 2009) produced higher yields and, in some cases, even reported $100 \%$ yields with very pure aluminum samples. The data for both $\mathrm{NaOH}$ and $\mathrm{KOH}$ show that there is a general trend of higher yields with higher temperatures, but this is not observed when one compares the different alkali concentrations. Tables 4 and 5 present the experimental data of the yields for plates that are $0.5 \mathrm{~mm}$ thick.

Based upon the results in Tables 4 and 5, the minimum hydrogen yield for the $0.5-\mathrm{mm}$ thick aluminum plates was $64 \%$ with a maximum yield of approximately $99 \%$. Higher temperatures resulted in an increase in the average yield for $\mathrm{NaOH}$ as well as $\mathrm{KOH}$. For the latter, particularly at $295 \mathrm{~K}$, the yield increased noticeably with temperature. Finally, in Tables 6 and 7, the results of hydrogen yields for 1 -mm thick aluminum plates are shown.

Table 2: Hydrogen yields (\%) for aluminum foil with $\mathrm{NaOH}$

\begin{tabular}{|c|c|c|c|c|c|}
\hline \multirow{2}{*}{ Temperature (K) } & \multicolumn{5}{|c|}{${\text { Concentration }\left(\mathbf{m o l}^{-1} \mathbf{- 1}\right)}$} \\
\cline { 2 - 6 } & $\mathbf{1}$ & $\mathbf{1 . 5}$ & $\mathbf{2}$ & $\mathbf{2 . 5}$ & $81.23 \pm 2.78$ \\
305 & $82.37 \pm 3.29$ & $82.41 \pm 2.04$ & $83.74 \pm 5.92$ & $81.25 \pm 5.49$ & $87.35 \pm 0.39$ \\
315 & $89.59 \pm 0.32$ & $89.01 \pm 0.41$ & $85.38 \pm 0.56$ & $84.64 \pm 2.88$ & $89.11 \pm 0.17$ \\
325 & $90.77 \pm 0.06$ & $91.65 \pm 1.03$ & $91.43 \pm 0.53$ & $88.79 \pm 0.23$ & $94.92 \pm 3.69$ \\
\hline
\end{tabular}


Table 3: Hydrogen yields (\%) for aluminum foil with $\mathrm{KOH}$

\begin{tabular}{|c|c|c|c|c|c|}
\hline \multirow{2}{*}{ Temperature (K) } & \multicolumn{5}{|c|}{ Concentration (mol'L $^{-1}$ ) } \\
\cline { 2 - 6 } & $\mathbf{1}$ & $\mathbf{1 . 5}$ & $\mathbf{2}$ & $\mathbf{2 . 5}$ & $\mathbf{3}$ \\
\hline 295 & $86.52 \pm 2.04$ & $85.83 \pm 3.12$ & $81.25 \pm 0.25$ & $88.63 \pm 1.81$ & $90.36 \pm 0.14$ \\
305 & $91.20 \pm 3.53$ & $91.33 \pm 0.25$ & $90.12 \pm 0.09$ & $90.44 \pm 0.28$ & $90.64 \pm 0.57$ \\
315 & $91.29 \pm 0.25$ & $90.88 \pm 0.65$ & $92.60 \pm 0.68$ & $92.59 \pm 0.31$ & $91.81 \pm 0.31$ \\
325 & $92.77 \pm 0.93$ & $95.96 \pm 0.30$ & $95.61 \pm 1.37$ & $94.07 \pm 1.35$ & $94.07 \pm 1.66$ \\
\hline
\end{tabular}

Table 4: Hydrogen yields (\%) for $0.5 \mathrm{~mm}$ thick aluminum plates with $\mathrm{NaOH}$

\begin{tabular}{|c|c|c|c|c|c|}
\hline \multirow{2}{*}{ Temperature (K) } & \multicolumn{5}{|c|}{ Concentration (mol'L $\mathbf{~}^{-1}$ ) } \\
\cline { 2 - 6 } & $\mathbf{1}$ & $\mathbf{1 . 5}$ & $\mathbf{2}$ & $\mathbf{2 . 5}$ & $\mathbf{3}$ \\
\hline 295 & $83.27 \pm 3.95$ & $96.87 \pm 3.00$ & $92.09 \pm 3.80$ & $96.80 \pm 2.95$ & $88.31 \pm 2.99$ \\
305 & $96.65 \pm 1.83$ & $98.49 \pm 0.41$ & $96.22 \pm 0.37$ & $95.16 \pm 1.90$ & $98.66 \pm 0.25$ \\
315 & $99.01 \pm 0.18$ & $97.62 \pm 0.59$ & $94.97 \pm 0.49$ & $98.78 \pm 1.41$ & $99.10 \pm 0.15$ \\
325 & $96.15 \pm 0.43$ & $98.25 \pm 0.35$ & $94.17 \pm 2.12$ & $99.91 \pm 2.02$ & $96.10 \pm 0.41$ \\
\hline
\end{tabular}

Table 5: Hydrogen yields (\%) for $0.5 \mathrm{~mm}$ thick aluminum plates with $\mathrm{KOH}$

\begin{tabular}{|c|c|c|c|c|c|}
\hline \multirow{2}{*}{ Temperature (K) } & \multicolumn{5}{|c|}{${\text { Concentration }\left(\mathbf{m o l}^{-\mathbf{1}} \text { ) }\right.}$} \\
\cline { 2 - 6 } & $\mathbf{1}$ & $\mathbf{1 . 5}$ & $\mathbf{2}$ & $\mathbf{2 . 5}$ & $\mathbf{3}$ \\
\hline 295 & $64.81 \pm 4.70$ & $72.17 \pm 0.48$ & $71.67 \pm 2.76$ & $89.04 \pm 1.21$ & $95.60 \pm 1.24$ \\
305 & $81.47 \pm 8.29$ & $99.10 \pm 0.04$ & $89.44 \pm 0.40$ & $90.70 \pm 4.66$ & $99.40 \pm 0.11$ \\
325 & $98.65 \pm 0.16$ & $97.60 \pm 0.83$ & $99.06 \pm 0.32$ & $97.28 \pm 1.91$ & $99.74 \pm 0.07$ \\
& $99.10 \pm 0.90$ & $94.24 \pm 0.35$ & $99.96 \pm 0.03$ & $99.15 \pm 0.84$ & $98.87 \pm 1.09$ \\
\hline
\end{tabular}

Table 6: Hydrogen yields (\%) for $1 \mathrm{~mm}$ thick aluminum plates with $\mathrm{NaOH}$

\begin{tabular}{|c|c|c|c|c|c|}
\hline \multirow{2}{*}{ Temperature (K) } & \multicolumn{5}{|c|}{ Concentration $\left(\mathrm{mol}^{\cdot} \mathrm{L}^{-1}\right)$} \\
\hline & 1 & 1.5 & 2 & 2.5 & 3 \\
\hline $315 \mathrm{~K}$ & $89.42 \pm 3.58$ & $94.94 \pm 0.44$ & $90.01 \pm 5.76$ & $95.03 \pm 2.98$ & $93.95 \pm 3.21$ \\
\hline $325 \mathrm{~K}$ & $96.63 \pm 1.22$ & $95.17 \pm 1.94$ & $96.61 \pm 3.56$ & $99.43 \pm 0.53$ & $98.83 \pm 0.21$ \\
\hline $335 \mathrm{~K}$ & $97.81 \pm 2.08$ & $97.81 \pm 1.30$ & $97.08 \pm 0.83$ & $97.97 \pm 0.08$ & $99.23 \pm 0.30$ \\
\hline $345 \mathrm{~K}$ & $96.88 \pm 2.76$ & $98.21 \pm 1.39$ & $99.60 \pm 0.38$ & $99.74 \pm 0.06$ & $96.80 \pm 3.80$ \\
\hline
\end{tabular}

Table 7: Hydrogen yields (\%) for $1 \mathrm{~mm}$ thick aluminum plates with $\mathrm{KOH}$

\begin{tabular}{|c|c|c|c|c|c|}
\hline \multirow{2}{*}{ Temperature (K) } & \multicolumn{5}{|c|}{ Concentration (mol $\mathbf{L}^{\mathbf{- 1}}$ ) } \\
\cline { 2 - 6 } & $\mathbf{1}$ & $\mathbf{1 . 5}$ & $\mathbf{2}$ & $\mathbf{2 . 5}$ & $\mathbf{3}$ \\
\hline 315 & $94.65 \pm 1.32$ & $92.58 \pm 2.02$ & $70.81 \pm 7.26$ & $97.83 \pm 1.83$ & $81.29 \pm 2.10$ \\
325 & $94.09 \pm 4.93$ & $96.59 \pm 3.23$ & $96.97 \pm 0.43$ & $83.93 \pm 2.27$ & $99.56 \pm 0.04$ \\
335 & $98.45 \pm 0.25$ & $98.21 \pm 1.66$ & $99.29 \pm 0.48$ & $99.19 \pm 0.06$ & $98.47 \pm 0.23$ \\
345 & $99.37 \pm 0.29$ & $99.18 \pm 0.16$ & $99.18 \pm 0.33$ & $98.76 \pm 1.05$ & $99.38 \pm 0.003$ \\
\hline
\end{tabular}

According to the data in Tables 6 and 7, there are also high hydrogen yields for the 1-mm aluminum plates, ranging from 80 to $99 \%$. Based on all of the data for the yields presented in Tables 2-7, we can conclude that there is no significant difference in hydrogen yield when using $\mathrm{NaOH}$ or $\mathrm{KOH}$ as a catalyst.

\section{Kinetic Parameters}

The kinetics of the hydrogen generation were evaluated according to classical models for nonhomogeneous reactions available in the literature
(Levenspiel, 1999). Such models take into account the chemical reaction controlling step in Equation (2) and the mass-transfer controlling step, Equation (3):

$\mathrm{X}_{\mathrm{Al}}=\mathrm{k}_{\exp } \mathrm{t}$

$\mathrm{X}_{\mathrm{Al}}^{2}=\mathrm{k}_{\mathrm{mt}} \mathrm{t}$

In Equations (2) and (3), $\mathrm{X}_{\mathrm{Al}}$ is the chemical conversion expressed as aluminum, $\mathrm{k}_{\mathrm{exp}}$ and $\mathrm{k}_{\mathrm{mt}}$ are the experimental parameters related to the reaction and mass-transfer controlling steps, respectively, in $\min ^{-1} ; \mathrm{t}$ 
is the time expressed as min. The relations above are valid for a flat plane geometry, because the aluminum samples used present this geometrical shape. Expressions for spherical geometry are also commonly used (when experiments are performed with aluminum particles) and are also described in Levenspiel (1999).

The order of the model in the reaction controlling step is calculated from different values of $k_{\text {exp }}$ evaluated over all the concentration range of the alkali solutions, according to Equations (4) and (5):

$$
\begin{aligned}
& \mathrm{k}_{\exp }=\frac{\mathrm{k}_{\mathrm{r}} \mathrm{C}_{\mathrm{OH}}{ }^{\mathrm{n}}}{\rho_{\mathrm{Al}} \mathrm{L}} \\
& \log \mathrm{k}_{\exp }=\log \left(\frac{\mathrm{k}_{\mathrm{r}}}{\rho_{\mathrm{Al}} \mathrm{L}}\right)+\mathrm{n} \log \mathrm{C}_{\mathrm{OH}}
\end{aligned}
$$

where $\mathrm{k}_{\mathrm{r}}$ is the intrinsic reaction velocity, in mol ${ }^{(1-\mathrm{n}) \text {. }}$ $\mathrm{cm}^{(3 \mathrm{n}-2)} \cdot \mathrm{min}^{-1}, \mathrm{n}$ is the apparent reaction order in relation to the alkali concentration $\mathrm{C}_{\mathrm{OH}}$, in $\mathrm{mol} \mathrm{cm}^{-3}$, $\rho$ is the molar aluminum density, in mol $\mathrm{cm}^{-3}$ and $\mathrm{L}$ is the metal width or metal thickness, in $\mathrm{cm}$. The value of $\mathrm{n}$ was found to be close to unity for every sample and alkali, which gives a first-order reaction in relation to alkali concentration, before the masstransfer effects become important. An example of the

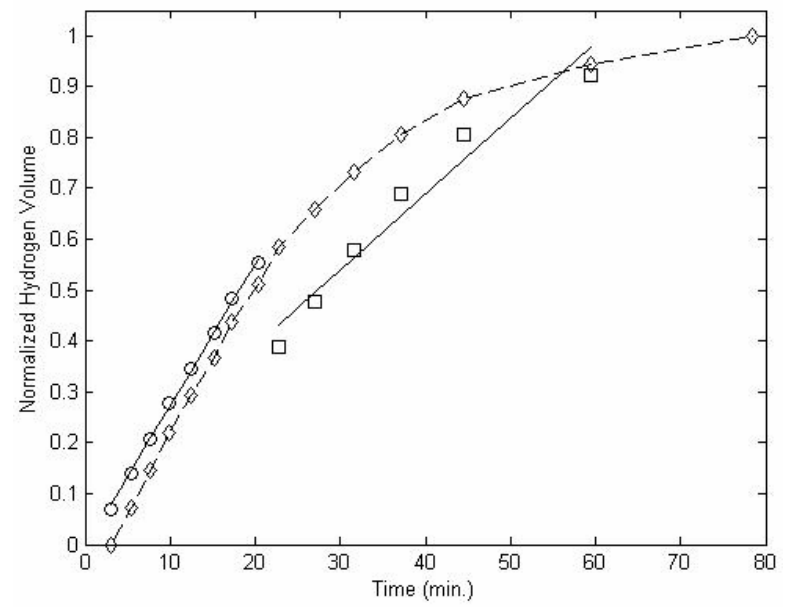

Figure 12: Curve fitting of experimental data for consumption ( $1 \mathrm{~mm}$ thick aluminum plates) in the presence of $1 \mathrm{~mol}^{-1} \mathrm{NaOH}$ at $345 \mathrm{~K}$. $-\diamond$ Normalized Hydrogen Volume, - - - Experimental points and regression curve (Equation (2)) for the chemical controlling step, - $\square$ - Experimental points and regression curve (Equation (3)) in the mass transfer region. results obtained by applying Equations (2) and (3) is illustrated in Figure 12. The normalized volume of hydrogen is also plotted in Figure 12 in order to compare the transition between the reaction controlling step and the mass transfer limiting step, as a result of the change in the slope of the normalized volume.

The adjustments of the regression models $\left(\mathrm{R}^{2}\right)$ were satisfactory $(0.9978$ in the chemically controlled step and 0.9506 in the mass transfer region). The linear Arrhenius model was used to estimate the activation energies of the reactions, as described in Equation (6):

$$
\ln \left(\mathrm{k}_{\exp }\right)=\ln \left(\mathrm{k}_{\exp , 0}\right)-\frac{\mathrm{E}}{\mathrm{R}}\left(\frac{1}{\mathrm{~T}}\right)
$$

where $\mathrm{E}$ is the activation energy, expressed as $\mathrm{J} \mathrm{mol}^{-1}, \mathrm{~T}$ is the absolute temperature, in $\mathrm{K}, \mathrm{R}$ is the ideal gas constant, in $\mathrm{J}_{\mathrm{mol}}{ }^{-1} \mathrm{~K}^{-1}$, and $\mathrm{k}_{\mathrm{exp}, 0}$ is the reaction specific velocity, expressed in $\mathrm{min}^{-1}$. The Arrhenius regression curves and the experimental points for aluminum foils in the presence of $\mathrm{NaOH}$ solution are shown in Figure 13.

The values of the activation energies obtained for all the experiments are shown in Tables $8(\mathrm{NaOH})$ and $9(\mathrm{KOH})$.

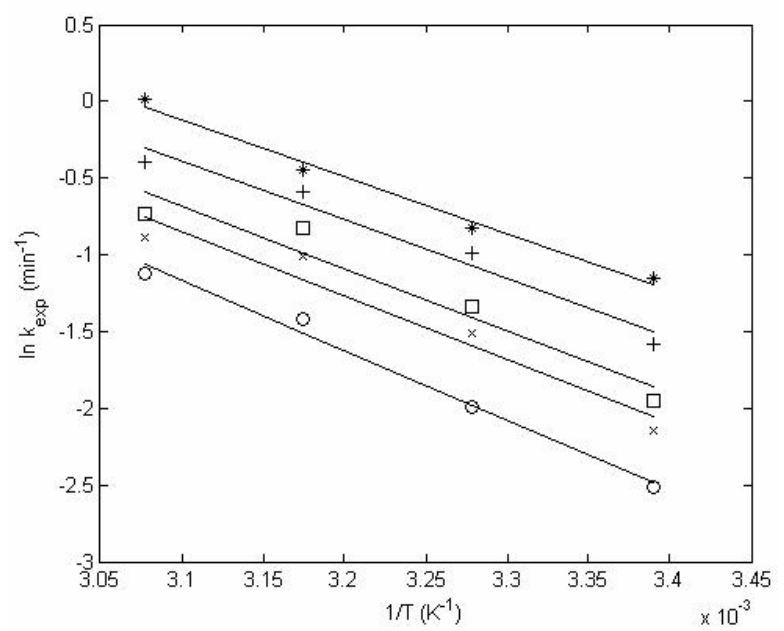

Figure 13: Arrhenius regression curves for aluminum foils in $\mathrm{NaOH}$ solutions. (०) $1 \mathrm{~mol}^{-1}$, (x) $1.5 \mathrm{molL}^{-1}$, (口) $2 \mathrm{~mol}^{-1},(+) 2.5 \mathrm{molL}^{-1},\left(^{*}\right)$ $3 \mathrm{~mol}^{-1}$ 
Table 8: Values of activation energies $\left(\mathrm{Jmol}^{-1}\right)$ in the presence of $\mathrm{NaOH}$ solutions

\begin{tabular}{|c|c|c|c|}
\hline $\begin{array}{c}\text { Concentration } \\
\left(\mathbf{m o l}^{\mathbf{- 1}} \text { ) }\right.\end{array}$ & $\begin{array}{c}\text { Activation Energy } \\
\text { (foils) }\end{array}$ & $\begin{array}{c}\text { Activation Energy } \\
(\mathbf{0 . 5} \text { mm thick plates) }\end{array}$ & $\begin{array}{c}\text { Activation Energy } \\
(\mathbf{1} \text { mm thick plates) }\end{array}$ \\
\hline 1.0 & 37912 & 55955 & 66827 \\
1.5 & 34395 & 55613 & 60380 \\
2.0 & 33624 & 54743 & 55501 \\
2.5 & 31777 & 53343 & 54125 \\
3.0 & 30872 & 51982 & 52932 \\
\hline
\end{tabular}

Table 9: Values of activation energies $\left(\mathrm{Jmol}^{-1}\right)$ in the presence of $\mathrm{KOH}$ solutions

\begin{tabular}{|c|c|c|c|}
\hline $\begin{array}{c}\text { Concentration } \\
\left(\mathbf{m o l}^{-\mathbf{1}} \mathbf{)}\right.\end{array}$ & $\begin{array}{c}\text { Activation Energy } \\
\text { (foils) }\end{array}$ & $\begin{array}{c}\text { Activation Energy } \\
(\mathbf{0 . 5} \text { mm thick plates) }\end{array}$ & $\begin{array}{c}\text { Activation Energy } \\
(\mathbf{1} \text { mm thick plates) }\end{array}$ \\
\hline 1.0 & 39805 & 62898 & 67766 \\
1.5 & 37788 & 60831 & 66180 \\
2.0 & 37272 & 59945 & 64790 \\
2.5 & 36643 & 58169 & 61020 \\
3.0 & 34247 & 57403 & 57451 \\
\hline
\end{tabular}

The comparison of the activation energies for both alkalis in different samples show a decrease in the values of these energies for higher alkali concentrations. This is expected because higher concentrations produce faster reaction rates, as already shown in Figures 5 and 6 . When comparing $\mathrm{NaOH}$ and $\mathrm{KOH}$ for each concentration, it is possible to verify that the activation energies of aluminum corrosion in $\mathrm{KOH}$ solutions are higher than the activation energies for corrosion in the presence of $\mathrm{NaOH}$ solution. From the data in Tables 8-9 it is possible to conclude that, for the same alkali concentration, the activation energies increase with increasing metal thicknesses. This is emphasized by comparing aluminum foils with the corresponding plates.

In the literature, similar results were obtained. Zhuk et al. (2006), studying high purity aluminum (greater than $99.9 \%$ ), reported activation energy of about $46-53 \mathrm{kJmol}^{-1}$ with $\mathrm{NaOH}$ as catalyst in a temperature range from $293 \mathrm{~K}$ to $343 \mathrm{~K}$. Values between 51.5 and $53.5 \mathrm{kJmol}^{-1}$ were also reported by Aleksandrov et al. (2003) in the presence of $0.1 \mathrm{~mol}^{-1} \mathrm{LaOH}$ for aluminum dust. Reactions between aluminum and water without auxiliary alkali were performed by adding lithium as a promoting metal and activation energies about $69 \mathrm{~kJ}^{\prime} \mathrm{mol}^{-1}$ were obtained by Rosenband and Gany (2010).

From the results obtained in this work and compared with activation energies evaluated in the literature, it is clear that such values are in the range between 50 and $70 \mathrm{kJmol}^{-1}$, depending on the alkali concentration, purity and shape of the aluminum samples.

\section{CONCLUSIONS}

From the results presented, it is possible to conclude that aluminum is an interesting alternative to generate high purity hydrogen. The reaction rate is strongly affected by temperature and the concentration of alkali, which acts as catalyst. Moreover, high yields are obtained that come close to the stoichiometric prediction under some conditions. The speed of aluminum consumption might be easily controlled by connecting such a system to a fuel cell or another device able to burn hydrogen to generate energy, especially for portable and medium scale electric devices. The main purpose of this work is demonstrating the possibility of using renewable aluminum as source of hydrogen. A complete analysis on the cycle is still under study in order to optimize hydrogen production, minimize energy costs and greenhouse gases emissions. Despite the high energy spent to produce aluminum, some studies have shown that the energetic and exergetic efficiency to generate hydrogen overcome the losses of aluminum production, according to Hiraki and Akiyama (2009), and the cost may be competitive for stationary power supply (Petrovic and Thomas, 2008).

\section{ACKNOWLEDGMENTS}

The first author would like to thank the CNPq (Brazilian National Council of Research and Development) for the financial support of his $\mathrm{PhD}$ thesis. 


\section{NOMENCLATURE}

\begin{tabular}{|c|c|c|}
\hline $\mathrm{C}_{\mathrm{OH}}$ & Alkali concentration & $\mathrm{mol}^{\circ} \mathrm{cm}^{-3}$ \\
\hline $\mathrm{E}$ & Activation Energy & $\mathrm{J} \mathrm{mol}^{-1}$ \\
\hline $\mathrm{k}_{\mathrm{exp}}$ & $\begin{array}{l}\text { Experimental parameter } \\
\text { of the reaction controlling } \\
\text { step }\end{array}$ & $\min ^{-1}$ \\
\hline $\mathrm{k}_{\mathrm{exp}, 0}$ & Specific reaction velocity & $\min ^{-1}$ \\
\hline $\mathrm{k}_{\mathrm{mt}}$ & $\begin{array}{l}\text { Experimental parameter } \\
\text { of the mass-transfer } \\
\text { controlling step }\end{array}$ & $\min ^{-1}$ \\
\hline $\mathrm{k}_{\mathrm{r}}$ & $\begin{array}{l}\text { Intrinsic reaction } \\
\text { velocity }\end{array}$ & $\begin{array}{l}\mathrm{mol}^{(1-\mathrm{n})} . \\
\mathrm{cm}^{(3 \mathrm{n}-2)} \cdot \min ^{-1}\end{array}$ \\
\hline $\mathrm{L}$ & Metal thickness & $\mathrm{cm}$ \\
\hline$n$ & Apparent reaction order & dimensionless \\
\hline $\mathrm{R}$ & Ideal gas constant & $\mathrm{J} \cdot \mathrm{mol}^{-1} \cdot \mathrm{K}^{-1}$ \\
\hline $\mathrm{t}$ & time & $\min$ \\
\hline $\mathrm{T}$ & Temperature & K \\
\hline $\mathrm{T}_{\text {water bath }}$ & $\begin{array}{l}\text { Temperature of the water } \\
\text { bath }\end{array}$ & K \\
\hline $\mathrm{T}_{\text {room temperature }}$ & Surrounding temperature & K \\
\hline $\mathrm{X}_{\mathrm{Al}}$ & $\begin{array}{l}\text { Molar conversion of } \\
\text { aluminum consumption }\end{array}$ & dimensionless \\
\hline
\end{tabular}

\section{Greek Symbols}

$\begin{array}{lll}\Delta \mathrm{H}_{\text {reaction }} & \text { Enthalpy of reaction } & \mathrm{kJ} \cdot \mathrm{mol}^{-1} \\ \mathrm{~mol} \mathrm{~cm}^{-3}\end{array}$

\section{Abbreviations}

HHV

Higher Heating Value

LHV

Lower Heating Value

SEM

Scanning Electron

Microscopy

EDS
$\mathrm{kJ}^{-1}$

$\mathrm{kJ} \cdot \mathrm{g}^{-1}$
Energy Dispersive X-Ray

Spectroscopic Analysis

\section{REFERENCES}

Aleksandrov, Y. A., Tsyganova, E. I., Pisarev, A. L., Reaction of aluminum with dilute aqueous $\mathrm{NaOH}$ solutions. Russ. J. Gen. Chem., v. 73, n. 5, p. 689694 (2003).

Brett, C. M., Brett, A. M. O., Electrochemistry Principles, Methods and Applications. Departamento de Química, Universidade de Coimbra, Portugal. Oxford University Press (1993).

Deng, Z., Ferreira, J. M. F., Physicochemical mechanism for the continuous reaction of $\gamma-\mathrm{Al}_{2} \mathrm{O}_{3}$-modified aluminum powder with water. J. Am. Ceram. Soc., 90, pp. 1521-1526 (2007).

Dow, E. G., Bessette, R. R., Seeback, G. L., Orndorff, C. M., Meunier, H., Vanzee, J., Medeiros, M. G., Enhanced electrochemical performance in the development of the aluminum/hydrogen peroxide semi-fuel cell. J. Power Sources, 65, pp. 207-212 (1997).

Emregül, K. C., Aksüt, A. A., The behaviour of aluminum in alkaline media. Corrosion Science, v. 42, pp. 2051-2067 (2000).

Holladay J. D., Hu, J., King, D. L., Wang, Y., An overview of hydrogen production technologies. Cat. Today, 139, 244-260 (2009).

Gerun, L., Paraschiv, M., Vîjeu, R., Bellettre, J., Tazerout, M., GØbel, B., Henriksen, U., Numerical investigation of the partial oxidation in a two-stage downdraft gasifier. Fuel, 87, pp.1383-1393 (2008).

Giltrap, D. L., McKibbin, R., Barnes, G. R. G., A steady-state model of gas-char reactions in a downdraft biomass gasifier. Sol. Wind, 74, pp. 85-91 (2003).

Grosjean, M. H., Zidoune, M., Roué, L., Hydrogen production from highly corroding Mg-based materials elaborated by ball milling. J. Alloys Compd., 404-406, pp. 712-715 (2005).

Hiraki, T., Akiyama, T., Exergetic life cycle assesment of new waste aluminum treatment system with co-production of pressurized hydrogen and aluminum hydroxide. Int. J. Hydrogen Energy, 34, pp. 153-161 (2009).

Kravchenko, O. V., Semenenko, K. N., Bulychev, B. M., Kalmykov, K. B., Activation of aluminum metal and its reaction with water. J. Alloys Compd., v. 397, pp.58-62 (2005).

Levenspiel, O., Chemical Reaction Engineering. Third Edition, John Wiley \& Sons, pp. 566-580 (1999).

Martínez, S. S., Sánchez, L. A., Gallegos, A. A. A., Sebastián, P. J., Coupling a PEM fuel cell and the hydrogen generation from aluminum waste cans. Int. J. Hydrogen Energy, 32, pp. 3159-3162 (2007).

Martínez, S. S., Benítez, W. L., Gallegos, A. A. A., Sebástian, P. J., Recycling of aluminum to produce green energy. Sol. Energy Mater. Sol. Cells, 88, pp. 237-243 (2005).

Parmuzina, A. V., Kravchenko, O. V., Activation of aluminum metal to evolve hydrogen from water. Int. J. Hydrogen Energy, 33, pp. 3073-3076 (2008).

Porciúncula, C. B., Marcilio N. R., Godinho M., Secchi A. R., Fluid dynamics simulation for design of a biomass gasifier. Computer Aided Chemical Engineering, 27, pp.1071-1076 (2009).

Petrovic, J., Thomas, G., Reaction of aluminum with water to produce hydrogen - A study of issues related to the use of aluminum for on-board 
vehicular hydrogen storage. U.S. Department of Energy (2008).

Rosenband, V., Gany, A., Application of activated aluminum powder for generation of hydrogen from water. Int. J. of Hydrogen Energy, v. 35, p.10898-10904 (2010).

Soler, L., Candela, A. M., Macanás J., Muñoz M., Casado, J., In situ generation of hydrogen from water by aluminum corrosion in solutions of sodium aluminate. J. Power Sources, 192, pp. 2126 (2009).

Soler, L., Macanás, J., Muñoz, M., Casado, J., Aluminum and aluminum alloys as sources of hydrogen for fuel cell applications. J. Power Sources, 169, pp. 144-149 (2007).

Tzimas, E., Filiou, C., Peteves, S. D., Veyret, J. B.,
Hydrogen storage: state-of-the-art and future perspective. European Commission - Joint Research Centre (2003).

Wang, H. Z., Leung, D. Y. C., Leung, M. K. H., Ni, M., A review on hydrogen production using aluminium and aluminium alloys. Renew \& Sustainable Energy Rev., 13, pp. 845-853 (2009).

Zainal, Z. A., Ali, R., Lean, C. H., Seetharamu, K. N., Prediction of performance of a downdraft gasifier using equilibrium modeling for different biomass materials. Energy Convers. \& Management, 42, pp. 1499-1515 (2001).

Zhuk, A. Z., Sheindlin, B. V., Kleymov, V., Shkolnikov, E. I., Lopatin, M. Y., Use of lowcost aluminum in electric energy production. $\mathrm{J}$. Power Sources, 157, pp. 921-926 (2006). 